\title{
MULHERES NA GENEALOGIA DE JESUS: UMA HISTÓRIA DE MARGINALIZAÇÃO E TRANSGRESSÃO
}

\author{
Liniker Xavier*
}

\section{RESUMO}

O evangelho de Mateus apresenta a genealogia de Jesus repleta de particularidades, sendo a principal delas a inserção de cinco mulheres no texto. A participação delas de forma destacada em uma linhagem é algo incomum. O que torna o episódio ainda mais excepcional é o fato de que todas as quatro mulheres que antecedem Maria possuem graves questões morais em suas biografias, todas ligadas à questão sexual. Tamar, que engravidou de Judá, seu sogro; Raabe, a prostituta cananeia; Rute, que seduziu a Boaz; Betsabéia, a mulher de Urias que, antes de tornar-se esposa, foi tomada por Davi contra a sua vontade; e, finalmente, Maria, a virgem que engravida por obra do Espírito Santo. São mulheres marginalizadas e transgressoras participando da linhagem do messias em um texto escrito especialmente para o judeu que cria em Jesus como Filho de Deus.

Palavras-chave: Genealogia; Mulheres; Jesus; Marginalização.

\section{WOMEN IN JESUS GENEALOGY: A STORY OF MARGINALIZATION AND TRANSGRESSION}

\section{ABSTRACT}

The Gospel of Matthew presents the genealogy of Jesus full of particularities, the main one being the insertion of five women in the text. Their participation prominently in a lineage is unusual. What makes the episode even more exceptional is the fact that all four women before Mary have serious moral issues in their biographies, all linked to the sexual issue. Tamar, who became pregnant with his father-

* Doutorando em Ciências da Religião ana Universidade Católica de Pernambuco (Unicap). Mestre em Teologia pela Unicap. Graduado em Comunicação Social com habilitação em Jornalismo pela Faculdade Joaquim Nabuco. Membro pesquisador do grupo de pesquisa Cristianismo e Interpretações, da Universidade Católica de Pernambuco. E-mail: linikerxavier@gmail.com. 
-in-law Judah; Rahab the Canaanite prostitute; Ruth seduced Boaz; Bethsaea, the wife of Uriah who, before becoming a wife, was taken by David against her will.; and finally Mary, the virgin who becomes pregnant by the Holy Spirit. They are marginalized and transgressive women participating in the lineage of the messiah in a text written especially for the Jew who believed in Jesus as the Son of God.

Keywords: Genealogy; Women; Jesus; Marginalization.

\section{MUJERES EN JESÚS GENEALOGÍA: UNA HISTORIA DE MARGINALI- ZACIÓN Y TRANSGRESIÓN}

\section{RESUMEN}

El Evangelio de Mateo presenta la genealogía de Jesús Ilena de particularidades, la principal es la inserción de cinco mujeres en el texto. Su participación prominente en un linaje es inusual. Lo que hace que el episodio sea aún más excepcional es el hecho de que las cuatro mujeres antes de Mary tienen serios problemas morales en sus biografías, todos relacionados con el tema sexual. Tamar, que quedó embarazada de su suegro Judá; Rahab la prostituta cananea; Rut sedujo a Booz; Betsaea, la esposa de Urías que, antes de convertirse en esposa, fue tomada por David en contra de su voluntad; y finalmente María, la virgen que queda embarazada del Espíritu Santo. Son mujeres marginadas y transgresoras que participan en el linaje del mesías en un texto escrito especialmente para los judíos que creían en Jesús como el Hijo de Dios.

Palabras clave: Genealogía; Mujeres; Jesús Marginación

\section{INTRODUÇÃO}

O comportamento do Jesus histórico nos evangelhos apresenta-se como uma afronta à sociedade que insistia em ferir ou diminuir a muIher. Nos evangelhos podemos ler os embates entre Jesus e os homens. Eram confrontos que aconteciam por conta de comportamentos que colocavam as mulheres em segundo plano, se apresentavam de forma legalista e, muitas vezes, opressora. Em sua carta apostólica "A Dignidade e Vocação da Mulher" (1988), o papa João Paulo II vai dizer que, "em todo o ensinamento de Jesus, como também no seu comportamento, não se encontra nada que denote a discriminação, própria do seu tempo, da mulher". Enquanto o título "filho de Abraão" é utilizado somente para homens em toda a Bíblia, Jesus vai chamar a mulher encurvada 
exatamente por este título. Mais tarde, em Lc 23.28, ela as chama de "filhas de Jerusalém". Jesus coloca as meretrizes à frente de muitos homens na entrada do reino de Deus (Mt 21.31). A postura adotada por Ele durante o seu ministério ultrapassa questões temporais e é uma demonstração da importância das garantias humanas para as mulheres de forma determinante e definitiva, como podemos ler:

A atitude de Jesus como primeiro libertador mundial da mulher e primeiro defensor da sua igualdade com o homem se destaca pela clareza, pela profundidade e pela coragem. Nessa libertação da muIher, Ele libertou o homem também do complexo de superioridade, da arrogância e do espírito de dominação. [...] Seu ato é semelhante à nova criação, como se Ele criasse a mulher de novo [...] (Emile EDDÉ, 2011, p. 29).

As mulheres permaneciam sujeitas às desigualdades e à exclusão nos tempos de Jesus. Elas permaneciam excluídas da vida religiosa e suas obrigações eram quase que exclusivamente voltadas ao serviço doméstico. Na comunidade patriarcal dos judeus, a mulher acompanhava o marido, mas não participava efetivamente das festas judaicas. Elas também não estavam obrigadas a fazer as três orações diárias. Na sinagoga, tinham um lugar separado dos homens, que as enxergavam como uma figura da primeira mulher, Eva. Deste modo, nos tempos de Jesus, as mulheres seguiam sendo vistas como símbolo de sedução e os homens precisavam ter cuidado para não cair em suas armadilhas. De acordo com o Talmude, a oração diária dos homens incluía a expressão "obrigado Deus, porque não me criaste pagão, escravo ou mulher". Também era proibido que uma mulher passasse entre dois homens.

Os encontros de Jesus com as mulheres e a sua forma de relacionar-se com elas deixa clara uma das suas bandeiras na pregação do Reino de Deus: a luta contra as estruturas que oprimiam e diminuíam o feminino, comprometendo a sua dignidade. É interessante notar que Jesus nunca as coloca acima dos homens (nem eles acima das mulheres). Também não as privilegia de algum modo excepcional. O que Jesus faz é conferir-lhes a dignidade humana, comum a todos os seres humanos. Mas só a fato das mulheres terem os mesmos direitos humanos que os 
homens já era o suficiente para que isto fosse encarado com incômodo.

A postura de Jesus nos evangelhos ressalta a não existência de duas doutrinas morais diferentes, uma para o homem e outra para a mulher. A maneira como Jesus se comporta com elas esclarece o equilíbrio das obrigações entre homens e mulheres. É interessante destacarmos as várias figuras femininas que aparecem nas parábolas contadas por Jesus. Elas aparecem na parábola das dez virgens e também na da dracma perdida. Ao falar da oferta da viúva, uma mulher duplamente em desvantagem (mulher e pobre), Jesus eleva o status dela e a coloca acima de muitos, trazendo-a como modelo para homens e mulheres.

O papa João Paulo II destacou que desde o início do ministério de Jesus as mulheres demonstraram uma sensibilidade especial com a causa, o que ele chama de "uma característica de sua feminilidade". Esta relação especial, aponta João Paulo II, pode ser verificada também quando Cristo dá prioridade a elas em alguns encontros:

As mulheres são as primeiras junto à sepultura. São as primeiras a encontrá-la vazia. São as primeiras a ouvir: "Não está aqui, porque já ressuscitou, como tinha dito" (Mt 28.6). São as primeiras a abraçar-lhe os pés (cf. Mt 28.9). São também as primeiras a serem chamadas a anunciar esta verdade aos apóstolos (cf. Mt 28.1-10; LC 24.8-11) (JOÃO PAULO II, 1988, p. 62).

Na via dolorosa, uma multidão de mulheres segue Jesus "batendo no peito e se lamentando por ele”. Aos pés da cruz, Cristo está cercado por mulheres. Após o episódio da ressureição, Jesus não somente deixa-se ver primeiramente pelas mulheres como também pede que elas, as mulheres, anunciem a boa nova. Jesus também não adota um filtro diferenciado para a escolha das mulheres com quem trata. Mulheres que transgrediram publicamente são recebidas por ele também de forma pública e, ainda que com suas transgressões, têm a sua dignidade restaurada enquanto pessoas humanas. Um trabalho de resgate que oportuniza a estas, as transgressoras, a retomada de suas vidas.

$O$ resgate do respeito às mulheres feito por Cristo nos evangelhos ultrapassa as esferas temporais e físicas e alcança também a esfera espiritual. São mulheres que antes não podiam por elas mesmas chegar-se a 
Deus, podendo agora tocar e conversar com Jesus sem a intermediação de homens, considerados mais aptos do que elas para participarem da vida espiritual do seu povo. Elas finalmente não precisavam adotar o comportamento e as características dos homens para se tornarem pertencentes ao divino. Em meio a este cenário, a perícope de Mt 1.117 apresenta a genealogia de Jesus com a presença de cinco mulheres. Com a inclusão de Maria, a mãe de Jesus, estas cinco mulheres possuem histórias marcantes e questionáveis quando analisadas à luz da moral do seu tempo. Elas enfrentaram o preconceito e a resistência.

O evangelho de Mateus apresenta a genealogia de Jesus repleta de particularidades. A participação feminina de forma destacada em uma linhagem é algo incomum. O que torna o episódio ainda mais excepcional é o fato de que todas as quatro mulheres que antecedem Maria possuem graves questões morais em suas biografias, todas ligadas à questão sexual. Tamar engravidou de Judá, seu sogro; Raabe é uma prostituta cananéia; Rute seduziu a Boaz; e Betsabéia é a mulher de Urias que, antes de tornar-se esposa, foi, contra vontade dela, tomada por Davi. Finalmente temos Maria, a virgem que engravida por obra do Espírito Santo. São mulheres marginalizadas e transgressoras participando da linhagem do messias em um texto escrito especialmente para o judeu da comunidade mateana, que cria em Jesus como Filho de Deus.

\section{A TRANSGRESSÃO COMO MARCA DAS MULHERES NA LINHAGEM DE JESUS}

Há nas veias de Jesus sangue que descende de uma mulher que se fez passar por prostituta para garantir a efetividade dos seus direitos. Foi o que fez Tamar. Além de passar-se por prostituta, sua ação poderia ser considerada como adultério à luz do costume local, à época. Tamar, que a tradição rabínica vai concordar se tratar de uma cananéia (Richard BAUCKHAM, 1995, p. 313-329), vai, com a sua transgressão, reivindicar que as suas prerrogativas sejam observadas. Ela tinha o direito de manter viva a descendência de seu marido e lutou para que esta observância fosse devidamente atendida (Gn 38.6-26). Para Ivoni Reimer, são as mulheres que "vão escancarar a vida de Jesus" no evangelho de Mateus: 
Isso é um recurso pedagógico para indicar o lugar protagonista de mulheres nas comunidades mateanas: por meio do registro da memória das grandes mulheres matriarcas junto à história dos grandes homens do passado se constroem argumentos para a centralidade, legitimidade e autoridade de mulheres na história atual. Não se trata de encaixar algumas mulheres na história patriquiriarcal, mas elas ali estão questionando tradições, agindo proativa e autonomamente no seio e na contramão dessas tradições. Elas não o fazem por causa das possibilidades que o contexto e a situação permitem, mas roem e alargam essas possibilidades que se revelam como limitações (Ivoni REIMER, 2013, p. 29-30).

Estrangeira e viúva, Tamar era agora uma transgressora subversiva e o sangue de Jesus parece reivindicar para si a postura de sua destacável ancestral. Em Mt 10.34 lemos Jesus afirmar que não veio trazer a paz para a terra, mas a espada, pondo os filhos contra os pais e as noras contra as sogras de modo que os piores inimigos dos homens seriam os seus familiares. É este Jesus, filho também de Tamar que, como ela, foi além dos laços sanguíneos para garantir seus propósitos. É da linhagem de Tamar este Jesus que, mais à frente, em Mt 10.39 afirma que "quem achar a sua vida perdê-la-á; e quem perder a sua vida, por amor de mim, achá-la-á”. É uma condenação aos que agem por interesse próprio somente, achando sempre a sua vida em detrimento da dos outros, especialmente em detrimento de Jesus. Tamar é das que, de certa forma, abriu mão de sua imagem, não achando a sua vida, para fazer valer seus direitos, sem medos.

A história de Tamar descortina novos olhares sobre a cananéia de Mateus 15.21-28. Esta também transgrediu ao procurar para si as migalhas que caem da mesa de seus donos para os cachorrinhos. Como Tamar defendeu a memória e descendência de seu marido, esta cananéia pede pela vida de sua filha, tornando-se sujeita numa história onde o protagonismo não era dela, já que Jesus afirma vir para as ovelhas perdidas do povo de Israel. Ivoni Reimer (2013, p. 30) analisa a presença de Tamar na linhagem de Jesus tratando sua memória como uma forma de fortalecimento para as lideranças femininas, que devem "continuar construindo história inclusiva e transgressiva de práticas religiosas que segregavam por causa de gênero e etnia”. Desta forma, continua Ivoni 
Reimer, a inserção de Tamar na genealogia é um ato "profundamente político-teológico". Ainda:

Ela se torna uma prostituta para ter seus direitos segurados. Se torna uma adúltera para ser mãe. Ter que transitar estes caminhos na margem desmascara a história patriarcal do clã de Judá. E desvendando o lado não oficial da história está participando da história da salvação (Ivoni REIMER, 1997, p. 147).

Cananeia, Raabe, a partir de sua transgressão, ao invés de tornar-se vítima, passa para a posição de protagonista da história. Ela é uma mulher que tem propriedade dentro das questões políticas de seu povo. Um conhecimento que a levou à condição de ponderar e avaliar estratégias políticas que pudessem garantir a sua existência e a de sua família. É subversiva quanto à legislação local e não se intimida na hora de escolher o lado de Israel, mesmo que isto envolvesse a transgressão da ordem civil do seu próprio povo. Em Mateus, Raabe não é julgada por sua atuação como prostituta, mas é reconhecida como matriarca. Em carta endereçada aos coríntios, Clemente afirma que por causa de sua fé e hospitalidade, Raabe, a prostituta, se salvou. Clemente afirma ter sido "Jesus, o Filho de Deus" o mandante dos espiões para Jericó. Ainda em sua carta ele vai afirmar que o vermelho do cordão pendurado por Raabe torna "evidente que, pelo sangue do Senhor, viria a redenção para todos aqueles que cressem e esperassem em Deus". Deste modo, Clemente aponta que esta é uma mulher em que houve não apenas a fé, mas o dom da profecia (Richard BAUCKHAM, 1995, p. 313-329).

Para Ivoni Reimer (2013, p. 31) a inserção de Raabe na genealogia de Jesus pode ter conexão com o fato de que "no período pós-guerra romana, muitas mulheres talvez se encontrassem em situação semelhante à da matriarca". Clécia Peretti e Ângela Natel (2014, p. 339) destacam que Mateus coloca Raabe na genealogia de Jesus possivelmente através de fontes extra bíblicas que ele encontrou, contendo informações e dados para afirmar que ela foi a mãe de Boaz. A condição dela possui três agravantes que poderiam corroborar para o seu processo de marginalização. Além de mulher, era prostituta e estrangeira. Apesar disso, 
sua ação para salvar o povo de Israel (ela é protagonista neste processo) é suficiente para se sobrepor aos possíveis pontos questionáveis.

Buscando autonomia para negociar livramento para sua própria vida e a de sua família, Raabe usa da solidariedade com os espias de Israel. A estrangeira recorre às suas convicções teológicas para justificar seu pedido. "O Senhor, o seu Deus, é Deus em cima nos céus e embaixo, na terra”, declara em Js 2,11. Raabe Uma cananéia que atribui a um Deus estranho as vitórias do inimigo de Jericó. O acordo dos espias com Raabe é uma exceção, já que viola as leis de guerra pregadas em Deuteronômio. Em Dt 20.16-18, a lei determina que quando Israel for conquistar cidades dentro da terra prometida, todos os moradores, sem exceções, devem morrer. Os cananeus são nominalmente citados no verso 17. As mortes seriam justificadas pelo fato de que estes povos poderiam levar o povo hebreu a praticar cerimônias idólatras, o que seria abominação. A voz de Raabe era firme e precisa. Seu discurso é seguro a ponto de ela ser a única ouvida pelos espias. Não há em todo o texto sagrado indícios de que aqueles dois homens enviados para espiar a terra tenham ouvido alguém além de Raabe. Tudo o que precisava ser dito foi colocado pela estrangeira prostituta. O que leva à tomada de Jericó são as considerações de Raabe. Em Josué 2.24 lemos as recomendações dos espias dadas a Josué: "Certamente o Senhor tem dado toda esta terra nas nossas mãos, pois até todos os moradores estão atemorizados diante de nós". Estas afirmativas estão baseadas unicamente no testemunho de Raabe. A hospitalidade e solidariedade de Raabe para com os espias foram as garantias da tomada daquela terra. Sobre esta questão da solidariedade o evangelista Mateus registra Jesus afirmando em Mt 10.40 que quem recebe os seus discípulos, recebe ao messias e, quem o recebe, está recebendo aquele que o enviou. O texto mateano faz um paralelismo com o perfil da personagem.

Viúva e estrangeira, Rute decidiu ser fiel aos laços que mantinha com sua sogra, Noemi. De acordo com Clécia Peretti e Ângela Natel,

Ela quis dizer que pretendia cuidar do sepultamento de Noemi e dos rituais relacionados à sua morte, e que seria enterrada no mesmo lugar que sua sogra. Essa seria uma preocupação comum para uma viúva sem filhos, por isso o compromisso de Rute teve um significado 
muito profundo para Noemi. Ser enterrada no mesmo túmulo da família de Noemi seria uma garantia adicional de que Rute continuaria a receber as provisões necessárias mesmo depois da morte da sogra (Clécia PERETTI; Ângela NATEL, 2014, p. 342).

Rute correu o risco da rejeição por parte da comunidade na qual ela agora queria estar inserida. Ainda assim, decide abrir mão de viver sua vida para cuidar de sua sogra, apresentando também sua solidariedade à situação de Noemi, viúva migrante como ela. Sua vida passa a funcionar como redenção para a vida da mãe de seu marido. A fidelidade de Rute teve de se aliar à sua perspicácia para que ela pudesse superar sua condição marginalizada. É a moabita que sugere ir às plantações de Boaz. Em Rt 2 o leitor é apresentado ao parente de Elimeleque, marido de Noemi, já no primeiro versículo, mas é a própria Rute quem sugere, no versículo seguinte, catar as espigas "atrás daquele em cujos olhos achar graça".

A exemplo das outras mulheres da genealogia de Jesus, a matriarca Rute se coloca como protagonista da história, tomando a iniciativa e insistindo nos seus propósitos. Apesar de declarar a Noemi “o teu povo é o meu povo e o teu Deus é o meu Deus", Rute é conhecida por ser a viúva moabita. Em Rt 2.6, um dos trabalhadores de Boaz destaca para ele que esta é a moça moabita que voltou com Noemi dos campos de Moabe. Em 2.10 ela questiona Boaz sobre a sua situação e quer saber por que acha graças aos olhos dele sendo uma estrangeira. Rute é despedida por Noemi quando esta se dá conta de que não teria marido para sua nora. Apesar da desobrigação, é Rute quem assume a responsabilidade por sua sogra, por escolha sua. Foi a estrangeira moabita quem usou de misericórdia com para com a sua sogra. A moabita agora é bem-aventurada segundo o Jesus de Mt 5.7, que considera felizes os que têm misericórdia dos outros, pois Deus terá misericórdia dos misericordiosos. Em mais uma das aproximações do texto mateano com o perfil das transgressoras, Jesus aparece como o estrangeiro que precisa de hospedagem e hospedar a um dos seus é como hospedar a ele (Mt 25.35). Ivoni Reimer afirma que a sua presença na genealogia de Jesus se justifica porque "a igreja, especialmente as mulheres, precisam tanto de perspicácia quanto do conhecimento legal de sua condição dentro do Império Romano para poderem sobreviver com astúcia e amorosidade" (2013, p. 32). 
No caso de Betsabéia, Athalya Brenner (2001, p. 170) considera o fato de ela ser casada com um heteu suficiente para tê-la como estrangeira. Em II Sm 11.2 lemos que ela se lavava, marcando o fim do seu período de purificação, após a menstruação. Fica óbvio que Betsabéia não estava grávida antes de deitar-se com Davi. Urias não poderia ter sido o pai da criança. Sua única fala no episódio com Davi é "estou grávida". Não fica clara a reação de Betsabéia diante dos desejos de Davi, mas tudo corrobora para entendermos que aquela mulher não teve escolha. Em II Sm 11 é Davi quem determina as regras. Lemos no verso primeiro que ele "enviou a Joabe"; "mandou indagar quem era aquela mulher" no verso dois; "enviou Davi mensageiros", no verso quatro; "mandou dizer a Joabe" no verso seis. A ação pertence a Davi.

Não há detalhes do primeiro encontro entre o rei e a mulher de Urias, só sabemos que o ato foi consumado gerando a gravidez. Diferente das três primeiras mulheres da genealogia de Jesus, Betsabéia não toma de imediato o protagonismo da história. Ela é silenciada e, só mais tarde, vai exercer poder e protagonismo. No início de sua história, Betsabéia é descrita apenas como "uma mulher mui formosa à vista", ainda que mais à frente o narrador informe que ela é "filha de Eliã, mulher de Urias, o heteu". Informação esta que só é fornecida após o interesse de Davi sobre ela. O rei não precisava de cortesia alguma para tê-la, de modo que a manda buscar até a presença dele sem rodeios. Não é ele quem vai até ela, mas seus mensageiros. Poderia então Betsabéia deixar de atender ao chamado do rei de Israel? O relato de II Sm 11 é corrido a ponto de não deixar clara a reação daquela mulher, se é que houve alguma reação. Não há espaço para sentimentalismo algum no início da história entre Davi e a mulher de Urias, senão o desejo desenfreado de um rei disposto a ter aquela a quem ele deseja.

Há uma grande controvérsia a respeito da posição de culpada ou inocente com relação ao caso do adultério de Davi com Bate-Seba. Será que ela estava em condições de negar uma ordem do rei? Pelo $2 \mathrm{Sm} 11.4$, parece que ela não tinha muita escolha. O escritor bíblico diz "no caso de Urias, o heteu", e não "no caso de Bate-Seba, a adúltera", porque Davi tomou a mulher de Urias e depois tirou a vida dele, de acordo com a tradição hebraica. Higgs diz: "o adultério era um pecado contra o marido. Portanto, em caso de adultério, era sempre o 
homem que era lesado - sem importar se a mulher também estivesse sendo traída ou não" (Clécia PERETTI; Ângela NATEL, 2014, p. 343).

Nem mesmo no momento em que tem voz, em II Sm 12.5, ao anunciar sua gravidez, Betsabéia fala com Davi. Ela manda que um mensageiro leve o recado ao rei. O narrador a chama mais uma vez de "mulher". Em todo o capítulo doze, o nome da personagem só aparece uma única vez, no verso três, respondendo a dúvida de Davi. Ivoni Reimer (2013, p. 32) destaca que a inserção de Betsabéia na genealogia de Jesus segundo Mateus se deve talvez ao fato dos "sofrimentos causados pelas cruzes e violências do Império Romano contra Jesus e gente da comunidade, que fazem calar e clamar 'porque me abandonaste?', indicando que, também ali, pode nascer algo novo”. Desta forma, para a autora:

A tradição de mulheres matriarcas se tornou importante para a comunidade e o evangelho de Mateus, porque assim outras estrangeiras, prostitutas, adúlteras podem referir-se a elas, e nelas encontrar coragem e conforto. Podem olhar para essa tradição da história salvífica e (re)construir sua vida em solidariedade para com aquelas pessoas que, na contramão da história, se acolheram e foram acolhidas também por Jesus e vivem em seguimento a ele (Ivoni REIMER, 2013, p. 33).

A partir do momento em que Davi fica sabendo da gravidez de Betsabéia, a história contada em II Sm 12 passa a focar a relação entre o rei e Urias com os detalhes e pormenores não encontrados quando o agravo foi causado com Betsabéia. Ao contrário de sua mulher, Urias tem voz. Davi parece incomodado com a notícia da gravidez, manda que Urias venha até ele e sugere que o homem vá para a sua casa "lavar os pés", dando a entender que Davi queria criar ocasião para que o Urias pudesse, ao deitar-se com sua esposa, enganar-se a ponto de achar que o filho que ela esperava era dele. Mas, não é o que acontece. Urias se mostra fiel ao seu comandante e não vai até sua casa. Sua obstinação é tão forte que, conforme lemos em II Sm 12.13, mesmo após ser embebedado por Davi, ele não vai até sua mulher. Os desejos dos dois homens são confrontados: o rei incontido e o servo fiel. Para Leni Fernandes (2014, p. 120), a narrativa detalhada do episódio envolvendo 
Davi e Urias contrasta com a rápida comunicação do rei com Betsabéia como forma de apresentar o tamanho do erro de Davi.

\title{
MARIA EM UM PROCESSO DE MARGINALIZAÇÃO
}

Maria, a mulher que carregou Jesus em seu ventre, não aparece na genealogia segundo Mateus como um tipo de Sara, mas na galeria de mulheres com biografias marcadas por transgressões. Há uma problemática importante na perícope de Mt. 1.1-17, quando Maria surge na genealogia. No texto, são os homens que geram sua descendência. $O$ verbo gennáo (gerar) sempre vai colocar o homem como sujeito da ação. Isso acontece mesmo quando as quatro primeiras mulheres aparecem. Abraão gerou Isaque, Isaque gerou a Jacó, Jacó gerou a Judá e seus irmãos, e assim sucessivamente. Os homens são sujeitos. A expressão "ek tês" (algo como "gerou de") aparece antecedendo todas as mulheres da genealogia segundo Mateus, conforme lemos:

\author{
Mt. 1,3 - "ek tês Thamar" \\ Judá gerou de Tamar a Perez e a Zerá; \\ Mt. 1,5 - "ek tês Rhachab" \\ Salmom gerou de Raabe a Boaz; \\ Mt. 1,5 - "ek tês Rhouth" \\ Boaz gerou de Rute a Obede; \\ Mt. 1,6 - "ek tês tou Ouriou" \\ Davi gerou a Salomão da que foi mulher de Urias.
}

Maria apresenta uma ruptura nesta forma estabelecida. Em Mt. 1.16 lemos que Jacó foi o pai de José, "marido de Maria, da qual nasceu Jesus, que é chamado Cristo". O sujeito do verbo não é mais um homem, mas Maria, uma mulher. Diferente do que acontece com as quatro muIheres que a antecedem na genealogia, é em Maria que se concentra a ação, sem a participação de um homem, garantindo que o que nela foi gerado é do Espírito Santo. Em Mt. 1.18 lemos a preposição "ek", sempre associada às mulheres, desta vez associada ao Espírito Santo (ek pneumatos hagiou) na gravidez de Maria. O que acontece com ela remete ao que lemos no primeiro capítulo do Gênesis. Ali, o Espírito de Deus se movia por cima das águas de uma terra sem forma e vazia. Pelo poder do Espírito, sem a participação do ser humano, tudo se criou. 
Agora este poder se manifesta mais uma vez, como que em uma nova criação, conforme defende Ivoni Reimer (2013, p. 34), desta vez sobre uma mulher e, outra vez, sem a participação do homem. Sobre este poder criador, lemos ainda:

De que modo Jesus é filho de Davi? Versículos Mt. 18-25 respondem a esta pergunta. A elaboração de Mt 1,16 em 1,18-25 lembra um pouco a dupla história da criação em Gênesis: a breve referência a criação do homem em Gn 1,26-31 é elaborada em 2,4b-25. A iniciativa criadora de Deus, que afeta a criação toda, é operativa (Warren CARTER, 2002, p. 98).

No evangelho segundo Mateus, Maria aparece ainda no relato da visita dos reis magos, na fuga ao Egito, no retorno a terra de Israel e junto aos irmãos de Jesus. Mateus também trata do parto virginal de Maria e da paternidade legal de José. Neste evangelho, Maria não fala. Ela está desposada com José, comprometida para o casamento quando em Mt 1.18 engravida por obra do Espírito Santo. O silêncio de Maria no texto de Mateus não é necessariamente imposto pela narrativa mateana e, conforme lemos em Pedro Lima Vasconcellos (1997, p. 37) pode estar associado ao mundo da religião e da sociedade da época, onde o poder religioso e social passa pelos homens. A voz de Maria, nestas circunstâncias, poderia incriminá-la ao invés de defendê-la.

O leitor mateano suspeitava daquela gravidez e Mateus parece cuidadoso ao defender Maria com o silêncio dela. Este silêncio oferecido por Mateus foi mais eloquente e forte que qualquer fala que pudesse estar contida ali. José, chamado homem justo e, provavelmente, visto com mais simpatia pelo público de Mateus, é o personagem utilizado para defender e apontar para uma Maria vítima de tantas suspeitas. O leitor de Mateus convivia também com o judaísmo farisaico, marcado pelo legalismo e por práticas que não conversavam com o comportamento de Jesus a respeito das mulheres. Mateus usa a figura de José para criar empatia, defender Maria e abrir o evangelho para todas elas.

Na perícope que vai do verso 18 ao 25, ela é a figura principal, mesmo sem falar. É ela, e não ele, quem carrega a promessa de salvação. Ainda assim, Maria está inserida no sistema familiar patriarcal. No verso 
24 é José, o marido, quem “recebeu em sua casa sua esposa”. É José também quem põe o nome do menino de Jesus. Pela lei mosaica, como já vimos, Maria poderia ser condenada à morte por apedrejamento, já que engravidou e o filho não é de seu noivo. É um caso, segundo a lei, de adultério. Uma gravidez ilegítima. Sobre a importância do compromisso de Maria com José, lemos:

Trata-se de um casamento juridicamente ratificado, já que dava início a transferência da moça do poder paterno para o poder do marido, dando a este direitos legais sobre ela e concedendo à noiva, em muitos aspectos, o status de uma mulher casada. A segunda fase era o matrimônio propriamente dito, a transferência da moça para a casa do marido. Presumia-se que a moça era virgem no momento do noivado e, pelo menos na Galiléia, também por ocasião da conclusão do casamento (Jane SCHABERG, 1989, p. 119).

Maria, a exemplo das outras quatro mulheres, é cheia de coragem. Em algum momento, esta que é uma mulher que pode ser condenada à pena de morte, consegue admitir para José que está grávida e que ele não é o pai da criança. José poderia delatar Maria de forma pública, mas o texto de Mateus afirma que ele era um homem "justo e não queria difamá-la”. Por esta razão, a primeira decisão de José consiste em pedir o divórcio de forma privada, sem escândalos. A postura de José também é importante para entendermos a sua relação com Maria na estrutura social e familiar em que estavam inseridos. O que se quis dizer ao afirmar que José era um homem justo a ponto de não querer difamar a sua noiva?

Xavier Léon-Dufour (1996, p. 11) vai nos apresentar ao menos três possibilidades sobre a justiça de José. Primeiro, ele aponta que José pode ter sido justo perante a lei. Sendo Maria adúltera, nada mais justo perante a lei que repudiá-la. Sendo ele um homem bom, o faria em secreto. A segunda suspeita levantada sobre a justiça de José aponta que ele tinha convicção da castidade de Maria. Desde modo, de forma gentil e delicada, ele a repudia não como forma de castigá-la para cumprir a lei mosaica e fazer justiça, mas para de alguma forma protegê-la. José estaria convencido de que Maria era inocente. É a terceira opção a que Xavier Léon-Dufour (1996, p. 11) defende. A justiça de José se dá 
porque ele aceita o desígnio de Deus. Deus, por meio de José, supera as dificuldades que surgem por meio de um nascimento sem pai e é nesta perspectiva que a justiça de José surge. Ele teria reconhecido a não-participação humana na gravidez de Maria e não estava fazendo esforço algum para cumprir a lei ou ser complacente com um adultério. O esforço de José era não se passar por pai do filho de Deus. Sobre o fato de José não ter participação da gravidez, lemos:

Esta cena continua legitimando o lugar da audiência do evangelho nos propósitos de Deus. Assegura aos seguidores de Jesus que eles seguem alguém que veio à existência por ordem de Deus para cumprir a vontade e comissão de Deus (1,21-23). Nos papéis que Maria e José desempenham, e especialmente na eliminação da intermediação masculina, os vv. 18-25 oferecem também um poderoso exemplo de que os caminhos de Deus são distintos e em desacordo com comportamentos humanos convencionais. O exemplo desafia a comunidade para um modo de vida difícil, mas confiável (Warren CARTER, 2002, p. 98).

Maria agora está vivendo a mesma situação que as outras mulheres da genealogia. Sua história levanta dúvidas quanto aos seus valores e também quanto à sua vida sexual, assim como a vida de Tamar, que também teve uma gravidez suspeita ao seduzir o sogro. As antecessoras de Maria passaram pela mesma situação de suspeição. Raabe era uma prostituta de povo inimigo dos israelitas. Betsabéia é considerada adúltera e Rute é a moabita que seduz Boaz. Assim, Maria é também infratora, transgressora e marginalizada por estar fora dos padrões vigentes. Para o público de Mateus, não bastasse a suspeita da gravidez, há ainda a questão da possível aceitação de um pecado por José. Ele teria direito de aceitar Maria naquelas condições? Somente uma ordem vinda dos céus justificaria para o leitor a compreensão de José para com a gravidez de Maria. É o anjo quem pede a José para que ele faça o contrário do que pretendia. José, que pretendia deixar Maria em secreto, agora recebe em sonho a orientação de recebê-la. Sua justiça excede o mero cumprimento da lei e inclui Maria, ao invés de marginalizá-la. O Jesus de Mateus chama José a essa justiça: 
Mais uma vez o paradoxo: alguém ameaçado de não nascer por conta de um suposto pecado, tem a missão de salvar o povo de seus pecados. Anuncia-se quem será ele: aquele que veio chamar os pecadores, não os justos (Mt 9,13), reconhecido como "amigo dos publicanos e pecadores" (Mt 11,18). O justo José deve acolher e assumir a alguém que não vai chamá-lo, a menos que ele vá mais longe (Pedro Lima VASCONCELLOS, 1997, p. 39-40).

A aparição do anjo para tratar de Maria e de sua gravidez aconteceu durante um sonho de José. Sonhos são frequentemente usados por Mateus com relação à vida de Jesus. Em 2.12 os visitantes do oriente voltam a sua terra por outro caminho para evitar Herodes. No verso 13, José sonha mais uma vez e recebe a ordem de pegar o menino Jesus e Maria para irem ao Egito. No v. 19, José sonha pela terceira vez, agora ele pode voltar para Israel, já que Herodes estava morto. Ainda em Mt 2.22, José recebe mais instruções e vai para a Galiléia. Nos dois primeiros capítulos do evangelho de Mateus, José sonha quatro vezes. “José, filho de Davi", expressão utilizada pelo anjo em Mt 1.20, liga José diretamente a descendência de Jesus. Jesus e José, os dois filhos de Davi. A expressão cumpre a importante função de deixar clara que a legitimidade do messianismo de Jesus não passa pelo homem. Apesar de José ser chamado filho de Davi, Maria não precisa relacionar-se sexualmente com ele para gerar Jesus.

O drama da mulher que "achou-se ter concebido do Espírito Santo" é um fato inesperado. Era Maria uma adúltera para o leitor do primeiro século? Como ela poderia estar grávida? Como bem observa Vasconcellos (1997, p. 34), a voz passiva em 1.18 vai deixar clara a vergonha da situação a qual aquela mulher esteve exposta. Para ele, o fato de Mateus registrar que ela "achou-se grávida" ainda denuncia que a situação teve caráter público. Conforme afirma Bernard Scott (1991, p. 89), Maria está, ao mesmo tempo, publicamente humilhada e divinamente honrada. A situação em que se encontra a mãe de Jesus é semelhante à das outras mulheres na genealogia. Ela pode ser caracterizada como uma infratora da lei, quebrando os padrões sexuais da época. Sobre o registro desta gravidez suspeitosa, lemos: 
Para aqueles que lêem o texto, já está indicado em que termos o conflito está situado: é necessário aceitar o inusitado, transgredir convenções, reconhecer que, mais uma vez, padrões estabelecidos não conseguem sufocar o novo que vem de Deus. Quem é capaz de tal experiência e percepção? (Pedro Lima VASCONCELLOS, 1997, p. 35).

É na figura do pai legal de Jesus que o texto garante a sua descendência enquanto messias, da linhagem de Davi, da tribo de Judá. José aparece tendo a revelação do anjo confirmando a profecia de Isaías (a virgem ficará grávida e terá um filho chamado de Emanuel). Se em 1.1-17 Mateus afirma os direitos políticos e teológicos do messias ao colocá-lo junto de Abraão e Davi, em 1.22-23 ele aponta para o direito profético, momento em que Maria, mais uma vez, se torna personagem de destaque na perícope. Ela é a virgem grávida. Para Pedro Lima Vasconcellos (1997, p. 34), há que se chamar a atenção para o fato de que o filho que Maria carrega em seu ventre é “do Espírito Santo". Entretanto, ele questiona a compreensão da expressão e a sua adequação. O Espírito Santo vai exercer o papel de pai de Jesus junto à Maria ou vamos entender a expressão como a ação de Deus criando vida no útero, como as Escrituras citam em Jeremias e nos Salmos? Há uma ação de Deus sobre Maria que, inclusive, vai garantir o título messiânico ao que ela dá à luz. O questionamento de Pedro Lima Vasconcellos (1997, p. 35) se dá pelo fato de o autor afirmar que a ação do Espírito como pai de Jesus coloca Maria e todo o contexto em conformidade com os modelos patriarcais de família, quando, para ele, o que ocorre é justamente o contrário, ou seja, uma ruptura com o sistema então estabelecido.

Desta forma, a presença do Espírito na concepção virginal vai ser justificada quando analisada à luz do messianismo. Ali, na genealogia, o Espírito não toma a função de pai de Jesus, mas garante que o menino é o messias que acolhe o inusitado. A história que envolve Maria e Jesus rompe padrões e garante que as formas estabelecidas não podem atrapalhar ou suprimir o novo de Deus, ainda que este novo seja uma gravidez virginal e suspeita. Conforme Pedro Lima Vasconcellos (1997, p. 42), Mateus resgata a questão histórica em seu texto, mas teologizando-a. Os relatos iniciais envolvendo Maria, José e o menino Jesus no evangelho, destacam o cumprimento de uma série de profecias. Mt 
2.5-6 é a afirmação do profeta Miquéias. Em 5.2, Miquéias coloca Belém como o local do nascimento do messias. Já Oséias 11.1 aparece em Mt 2.15, tratando da fuga da família para o Egito. Em 2.17 de Mateus lemos sobre a matança dos inocentes, que aparece em Jeremias 31.15.

Ivoni Reimer (2003, p. 41) vai afirmar que a presença de Maria em Mateus se dá porque o evangelho quer justificar a profecia de Isaías 7.14, já que a mãe de Jesus não tem voz no texto. No entanto, por tudo o que Maria representa para a comunidade de Mateus, por todas as quebras de paradigmas, sua presença não parece ter unicamente a função de justificar um verso de Isaías. O texto de Mateus é ousado. Tanto a genealogia, quanto os relatos da gravidez de Maria representam um esforço hermenêutico do texto. Em 1.23, ele se afasta do texto da Septuaginta para traduzir hermeneuticamente o nome de Jesus, adicionando o "Deus conosco", o que denota que Mateus tinha consciência da hermenêutica que fazia do texto. Sobre isto, lemos:

A citação só está aí por ser fruto de um minucioso e delicado processo de reinterpretação, seja da história de Jesus, seja da ação de Deus que tem o tem por messias e presença sua no meio do povo. E, mais que uma função apologética, a citação da profecia compre uma função de legitimação no sentido estrito da palavra: assim, como a ação de José deverá legitimar a sua mulher e ao seu filho frente a sociedade patriarcal e as leis vigentes, o texto de Isaías os legitima teologicamente; legitima a gravidez ilegítima e aponta a surpresa. Daí vem a possibilidade de reconhecer a Deus no meio de nós (Pedro Lima VASCONCELLOS, 1997, p. 42).

O texto de Isaías não legitima somente a Jesus, mas a Maria e a sua gravidez. Ela é a que dá à luz ao "Deus Conosco" e, ao mesmo tempo em que o traz ao mundo, também o recebe ela mesma. $O$ "Deus Conosco" torna-se no evangelho segundo Mateus mais do que um modelo de sacrifício, mas de identificação com a experiência humana. O que Maria carrega identifica-se com ela e com a situação em que ela se encontra. O "Deus Conosco" é do cego, do mudo, dos pequeninos, dos publicanos e das meretrizes. Nele, "os cegos veem, os coxos andam, os leprosos são purificados, os surdos ouvem, os mortos são ressuscitados, e aos pobres é pregado o evangelho" (Mt 11.5). 
Em Mt. 2.13-23, José volta a receber a revelação de um anjo e foge para o Egito levando Maria e Jesus, para poupar a vida do menino da fúria de Herodes. Maria agora vive a experiência de ser estrangeira como as mulheres que a antecedem na genealogia de Jesus. Após o retorno para as terras de Israel, José, agora agente ativo da ação, decide viver com Maria e Jesus na cidade de Nazaré, por temer Arquelau, que governava a Judéia. Agora Maria só volta a aparecer no texto mateano no capítulo 12. José não faz mais parte do cenário onde agora constam também os irmãos e irmãs de Jesus. O messias passa a ser conhecido como o filho do carpinteiro e filho de Maria (Mt 13.55-56). Em Mt 12.4650, Jesus vai usar sua estrutura familiar para criar a família do Reino. Maria e os irmãos de Jesus chegam e pedem para falar com ele. Alguém leva o recado e recebe a resposta: "quem é a minha mãe? E quem são os meus irmãos? Aqui está a minha mãe e os meus irmãos”. De acordo com as palavras registradas por Mateus, "quem faz a vontade de Deus é irmão, irmã e mãe de Jesus”. Não é um processo de exclusão com os seus, mas de inclusão de todos os outros que cumprem estes requisitos, conforme lemos:

Jesus não exclui a sua mãe, suas irmãs e seus irmãos. Ele inaugura uma nova relação com eles na medida em que também os acolhe em seu discipulado, estendendo também sobre eles as suas mãos. Com isso, fica claro igualmente que Jesus evidencia que mulheres e homens, de maneira indistinta, participam do discipulado de pessoas iguais (Ivoni REIMER, 1997, p. 151).

Não há nada no texto de Mateus, nem na perícope específica, que denote algum demérito a Maria e seus outros filhos ou mesmo desprezo e polêmicas do tipo. Jesus usa a ocasião para instituir uma nova família: a família do Reino de Deus, que se baseia nestes valores, dos que cumprem a vontade do Pai, assim como Maria.

\section{PORQUE MATEUS INSERE MULHERES NA GENEALOGIA DE JESUS?}

A questão aqui não é somente porque as mulheres integram o texto, mas porque estas mulheres especificamente, as marginalizadas e transgressoras, em uma genealogia messiânica. Marshall Johnson (2002, 
p. 146ss) e Warren Carter (2002, p. 89ss) levantam alguns significados para a questão e, é a partir dos levantamentos destes autores, que apresentamos agora algumas das possíveis motivações da presença feminina no texto genealógico mateano. A primeira suposição afirma que a presença destas mulheres tem a função meramente de inseri-las, as mulheres, na linhagem de Jesus. Tamar, Raabe, Rute e Betsabéia estariam ali representando todas as outras mulheres que tiveram destaque na história de Israel e participação destacável dentro de seus povos, a exemplo de todas as outras que não puderam aparecer, como Sara e Rebeca, por exemplo. Carter (2002, p. 90) vai apontar que, os que defendem este ponto de vista afirmam que as mulheres da genealogia lembram as outras inominadas. Mas o texto genealógico de Mateus é parcial e oferece abertura para que fossem feitas opções. No entanto, se a intenção for apenas representação feminina, temos muitos outros exemplos menos controversos e mais respeitáveis para o público alvo do evangelho que poderiam ocupar o lugar destinado àquelas transgressoras. Não nos parece plausível.

Outra linha de raciocínio destaca que a menção das quatro mulheres tem a intenção de pregar a preocupação de Jesus com os gentios. Raabe era cananéia, como provavelmente Tamar, da mesma forma. Rute era moabita. No caso de Betsabéia, ela era israelita. Seu pai habitava ao sul de Hebron. Seu laço pagão é o marido hitita, Urias. Sobre Maria, não há informação alguma que a ligue com o paganismo. Marshall Johnson (2002, p. 176) aponta que este era o pensamento predominante entre os pais da igreja, entre eles Orígenes, em uma homilía sobre o evangelho de Lucas; Crisóstomos; e Ambrósio, em uma exposição de Lucas 3. Também seguiu este entendimento o reformador Lutero e o exegeta Alfred Plummer.

Aqui, cabe-nos questionar se, para admitir gentios na comunidade, Mateus considerou plausível trazer para a genealogia perfis com manchas morais que poderiam escandalizar o público da época. $\mathrm{O}$ evangelista não poderia garantir a inserção de gentios fazendo uso de personagens menos controversos? E porque apenas mulheres, e não homens e mulheres, se a questão não está relacionada ao gênero, mas à nacionalidade? Contudo, principalmente entre os reformistas do século 
XVI, esta é uma linha de raciocínio bastante aceita. Warren Carter (2002, p. 90) afirma que "a inclusão de pagãos como também de judeus nos propósitos de Deus e no povo da aliança é enfatizado por Abraão (Mt 1.1-2) e pelos magos, visitantes do oriente, no capítulo 2".

Uma última suposição menos consistente, antes de apresentarmos aquelas que nos parecem mais cabíveis, afirma que estas mulheres foram incluídas na genealogia de Jesus porque eram tidas como pecadoras. A participação delas na linhagem de Jesus é feita como um contraste entre elas e o messias que, sem pecado, tem poder para perdoá-las e aceitá-las. Este messias é fruto de uma linhagem pecaminosa, a de Davi. Warren Carter (2002, p. 92) não vê a suposição com simpatia. Para ele, esta é uma linha de pensamento que evoca o estereótipo negativo das mulheres. De fato, há que se ressaltar que, se a questão é tratar de pecadores, torna-se indiferente se eles, os pecadores, são homens ou mulheres. Além disso, pecadores por pecadores, a própria genealogia traz um bom número de homens inseridos em contexto de pecado, como o próprio Davi e ainda Acaz e Manassés. Os estudiosos Ernest Lohmeyer e Gerhard Kittel defendem aspectos desta interpretação. Marshall Johnson (2002, p. 180) aponta que, para eles, Deus pode usar o mais desprezado dos seres humanos para realizar seus propósitos.

De forma mais significativa, Raabe foi subsequentemente compreendida como modelo de fé (Hb 11,31) e Tamar de retidão (Gn 38,26). Tamar está também positivamente associada com Rute (Rt 4,12). Além disso, Maria não é vista como pecadora (Warren CARTER, 2002, p. 90).

A partir de agora vamos abordar as ideias mais consistentes e bem aceitas pelos estudiosos da genealogia de Jesus segundo Mateus, que investigam também o que fazem as mulheres neste espaço. A primeira delas enxerga o fator do incomum na vida de cada uma das mulheres apresentadas, incluindo a vida de Maria. As relações das cinco matriarcas com os homens vão apresentar-se sempre com um fator surpresa que foge ao que é culturalmente aceito em seu tempo. A primeira delas, Tamar, seduz o sogro, Raabe é prostituta e Rute é apresentada também como uma suposta sedutora. Betsabéia é uma mulher em adultério e Maria, desposada, é a grávida sob suspeita. Lee Levine (1988, p. 87) vai 
falar da instrumentalização do sexo pelas quatro primeiras mulheres. Raabe e Rute o usam como garantia para sua subsistência econômica. Tamar usa o sexo como motivo para viver. Ela precisa de um herdeiro para o seu marido. Para Betsabéia, o sexo foi instrumento de segurança política. As quatro mulheres têm a iniciativa e a convicção de que precisam empregar meios não usuais para ou proteger os seus interesses, ou superar obstáculos, ou as duas coisas. Maria também se enquadra desta forma, mas, diferente das outras, ela não se insere, mas é inserida. A vida das cinco é marcada por alguma irregularidade e todas as irregularidades são marcadas pela intervenção de Deus.

Elaine Wainwright (1991, p. 186ss) vai apontar uma interessante solução para a questão do feminino na genealogia de Jesus. Para ela, a genealogia é, na verdade, androcêntrica e patriarcal, ainda que as mulheres apareçam nela. É uma genealogia focada no homem porque, conforme aponta a autora, ela defende a herança através da linhagem masculina, além de ignorar as filhas em todo o texto. Desta forma, como Elaine Wainwright (1991, p. 190) vê as mulheres no texto de Mateus 1,1-17? Elas estariam ali porque vivenciaram situações em que colocaram em perigo a estrutura patriarcal. São mulheres que colocaram o poder dos homens em cheque, ocupando o protagonismo das cenas onde estiveram inseridas. São mulheres que aparecem na história fora de relações legitimadas por um casamento sólido que as apresente à sociedade patriarcal. Tamar era uma viúva fora do levirato e Raabe não é mulher ou filha de alguém, mas uma prostituta. Rute está sendo protegida por sua sogra Noemi e Betsabéia é a adúltera em uma relação extraconjugal com o rei Davi. Quanto a Maria, Elaine Wainwright (1991, p. 193) a aponta como a mulher que concebe sem a participação de um homem.

São cinco situações de subversão. As cinco rompem as estruturas sociais vigentes dos lugares onde se inserem. Todas elas estão à margem e quando Mateus as chama para o texto, está afirmando que o poder do messias não precisa necessariamente estar ligado a estruturas já fundamentadas e normatizadas pela sociedade porque ele mesmo se afirma sem precisar da ajuda do ser humano. Assim, conforme Warren Carter (2002, p. 92), "as margens não são esquecidas ou amaldiçoadas 
por Deus, mas decisivas para os seus propósitos". Lee Levine (1988, p. 88) também aponta uma solução para as mulheres da genealogia de Jesus. Estas são mulheres que não têm potencial na estrutura cultural ou socioeconômica, diz. A fé e o valor que elas carregam permite a consumação do plano divino. Em Mateus, elas apresentam o contraste com os homens de suas épocas. Homens que, ao contrário delas, não cumprem com seus papéis e deixam a desejar.

Tamar excede a justiça de Judá. Ele é injusto, ela, a justa. A sedução de Tamar existe graças à incapacidade e fracasso de Judá em garantir o mínimo: que os preceitos legais sejam cumpridos. De forma injusta, ele não dá seu filho a Tamar e, deste modo, fere o levirato. Tamar cumpre o seu papel por ela, por ele, por seu marido morto, por todos. O caso de Raabe segue o mesmo viés. Ela é a cananéia justa que se compromete com um Deus que não pertence ao seu povo. Enquanto o rei de Jericó quer exterminar o povo de Israel, ela, justa, acolhe os espias e garante a vitória dos hebreus. O rei é resistente a Deus, Raabe não apresenta resistência alguma. Seguindo as orientações de outra mulher, a sua sogra Noemi, Rute trabalha com toda sua persuasão para trazer Boaz para si. As circunstâncias em que está inserida a obriga a ir para o campo colher as espigas. Ali, ela, e não ele, garante a mudança de vida para aquele núcleo familiar. Betsabéia, sem o poder de Davi, é a que passa a ter poder sobre o reino de Israel. Em contraste com o rei, ela não faz uso de seu poder para abusos como os cometidos por ele. E Maria, mãe de Jesus, concebe do Espírito Santo enquanto José planeja deixá-la. Os planos dele são interrompidos pelo sonho com o anjo.

São mulheres aparentemente sem poder algum que contrastam com homens poderosos. Homens que nem sempre têm sucesso no cumprimento de suas responsabilidades, ofuscados pela forma firme como agem estas mulheres. Assim, como aponta Warren Carter:

Novamente nas margens encontramos a ação de Deus, um tema que continuará ao longo do evangelho. As mulheres representam a inclusão do marginal e excluído, a acolhida da comunidade a "todo status ou distinção negada pelos membros dos grupos da elite, a todo aquele cuja retidão mais elevada é menosprezada por estruturas de hierarquia" (Warren CARTER, 2002, p. 92). 
Ainda vale ressaltar aqui duas alternativas apontadas por Marshall Johnson (2002, p. 181). A primeira delas aponta que Mateus estaria refutando de forma consciente os ataques contra a legitimidade do nascimento de Jesus, apontando os chamados defeitos da linhagem messiânica. Estes defeitos não seriam as pessoas em si, mas as ações que foram obrigadas, de algum modo, a cometerem. Isso inclui prostitutas e pagãs. Por fim, o leitor judeu de Mateus não precisaria recorrer a outra literatura, senão a do seu próprio povo, para descobrir que a gravidez suspeita de Maria não é tão escandalosa assim quando a comparamos com outros fatos envolvendo mulheres inseridas no contexto messiânico. Desta forma, as quatro mulheres são tipos de Maria que preparam o leitor para a novidade do nascimento virginal de Jesus. É absolutamente plausível estas quatro mulheres entrarem de forma extraordinária ou irregular na genealogia de Jesus. Para Mateus, elas podem ter sim significado um tipo de Maria. A história da mãe de Jesus e da chegada de seu filho precisa ser preparada e as quatro mulheres cumprem esta função.

\section{CONSIDERAÇÕES FINAIS}

Uma série de fatores pode ter contribuído para a inserção destas cinco mulheres na genealogia de Jesus segundo o evangelho mateano. O fato de estas mulheres serem transgressoras, isoladamente, não serve de justificativa plausível, já que tantos dos homens que aparecem ali são tão transgressores quanto elas. São também mães. As quatro primeiras sempre fazendo referência à última, mãe do filho de Deus. A gravidez de Maria é escandalosa como a de Tamar e a marginaliza como a Rabe. Maria é Rute quebrando paradigmas e é Betsabéia chorando a morte de seu filho. São todas mulheres e mães participando do processo de salvação e todas elas em um momento crucial da história de seus povos. Estrangeiras recebidas por Jesus, que as chama e as aceita.

Todas as leituras apresentadas aqui possuem algum valor e Warren Carter (2002, p. 92) aponta uma importante observação ao dizer que o principal erro dos intérpretes é procurar somente uma explicação para o caso quando muitas suposições possuem intuições válidas e que poderiam e devem ser consideras. Esta genealogia parece possuir "uma 
agenda teológica, uma função sociológica e pastoral e uma contribuição narrativa (Warren CARTER, 2002, p. 85)”. A genealogia de Jesus com mulheres marginalizadas, transgressoras e gentias oferecem ao leitor de Mateus uma esperança. A esperança de participar dos planos e propósitos de Deus. E isto não de forma periférica, mas central. Esta é uma esperança que pertence a toda e qualquer pessoa, seja pobre, marginalizada ou doente.

\section{REFERÊNCIAS}

BAUCKHAM, Richard. Tamar's ancestry and Rahab's marriage: two problems in the Matthean genealogy. Novum Testamentum, v. 37, n. 4, 1995, p. 313-329.

BÍBLIA SAGRADA. Bíblia de Jerusalém (Ed. Revista). São Paulo: Paulus, 2002.

BÍBLIA SAGRADA. Bíblia Pentecostal (Ed. Revista e Corrigida). Rio de Janeiro: CPAD, 1995.

BRENNER, Athalya. A Mulher Israelita: papel social e modelo literário na narrativa bíblica. São Paulo: Paulinas, 2001.

CARTER, Warren. 0 evangelho de São Mateus: comentário sociopolítico e religioso a partir das margens. Grande comentário bíblico. São Paulo: Paulus, 2002.

EDDÉ, Emile. Jesus libertador da mulher. São Paulo: Paulus, 2011.

FERNANDES, Leni Soares Vieira. Imagens da mulher no Evangelho de Mateus: a construção de personagens femininas. Dissertação (Mestrado em Letras). Universidade Presbiteriana Mackenzie, São Paulo, 2014.

JOÃO PAULO II, Papa. Carta apostólica Mulieris dignitatem: sobre a dignidade e a vocação da mulher por ocasião do ano mariano. São Paulo: Paulinas, 1988.

JOHNSON, Marshall. The purpose of the biblical genealogies: with special reference to the setting of the genealogies of Jesus. Oregon: Wipf na Stock Publishers, 2002.

LÉON-DUFOUR, Xavier. Leitura do Evangelho segundo João. V II. São Paulo: Loyola, 1996.

LEVINE, Lee. Herod the great. New York: Doubleday, 1992.

PERETTI, Clécia; NATEL, Ângela. As mulheres na genealogia de Jesus no Evangelho de Mateus. Estudos Teológicos, v. 54, 2014, p. 333-349.

REIMER, Ivoni. Maria, Jesus e Paulo com as mulheres: textos, interpretações e história. São Paulo: Paulus, 2013.

REIMER, Ivoni. Não temais... Ide ver... E anunciai!: as mulheres no evangelho de Mateus. Revista de Interpretação Bíblia Latino-Americana, v. 27, 1997, p. 149-166.

SCHABERG, Jane. As antepassadas e a mãe de Jesus. Petrópolis: Concilium, 1989. 
SCOTT, Bernard Brandon. The birth of the reader. How gospels began. Semeia: Society of Biblical Literature, 1991.

VASCONCELLOS, Pedro Lima. Una gravidez sospechosa, el mesianismo y la hermeneutica: anotaciones sobre Mateo 1,18-25 Revista de Interpretación Bíblica Latinoamericana, v. 27, 1997, p. 28-46.

WAINWRIGHT, Elaine. Towards a feminist critical reading of the gospel according to Matthew. New York: Walter de Gruyter, 1991.

Submetido em: 8-10-2019

Aceito em: 21-11-2019 